\title{
Gas Chromatography-Mass Spectrometric Analysis of Essential Oil of Aerial Parts of Glycosmis parviflora (Sims) Little (Rutaceae)
}

\author{
Zhi Long Liu ${ }^{1 *}$, Kai Yang ${ }^{1}$, Peng Hua Bai ${ }^{1}$, Ligang Zhou ${ }^{2}$, Shao Liang Liu ${ }^{3}$, and \\ Qi Zhi Liu ${ }^{1}$ \\ ${ }^{1}$ Department of Entomology, ${ }^{2}$ Department of Plant Pathology, China Agricultural University, 2 Yuanmingyuan West Road, \\ Haidian District, Beijing 100193,China ${ }^{3}$ Department of Biology, Faculty of Preclinical Medicine, GuangXi Traditional Chinese \\ Medical University, Nanning 530001, China.
}

*For correspondence: Email: zhilongliu@cau.edu.cn; Tel.: +86-10-62732800; Fax: +86-10-62732800.

\begin{abstract}
Purpose: To investigate the chemical composition and toxicity of the essential oil of Glycosmis parviflora (Sims) Little aerial parts against root-knot nematode and two grain storage insects (maize weevil and red flour beetle).

Methods: Steam distillation of G. parviflora was carried out using Clavenger apparatus in order to extract its volatile oil. Gas chromatography/mass spectrometric (GC/MS) analysis (HP-5MS column) of the essential oil was performed and the toxicity of the oil determined by contact test.

Results: A total of 37 components comprising $98.7 \%$ of the essential oil were identified, of which (Z)-

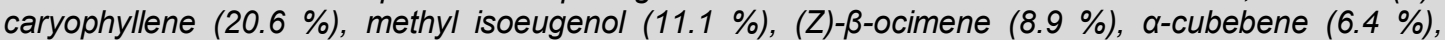
nerolidol (5.4\%), aromandendrene (4.9\%) and $\gamma$-pyronene $(4.7 \%)$ were found to be the major components. The essential oil possessed strong nematicidal activity against $M$. incognita with an $L C_{50}$ value of $92.84 \mu \mathrm{g} / \mathrm{ml}$. The essential oil of $\mathrm{G}$. parviflora exhibited strong contact toxicity against $S$. zeamais and $T$. castaneum adults with $L D_{50}$ values of 41.7 and $22.6 \mu \mathrm{g} / \mathrm{adult}$, respectively.

Conclusion: The study indicates that the essential oil of G. parviflora aerial parts has a potential for development into a natural insecticide/nematicide for control of nematodes and grain storage insects.
\end{abstract}

Keywords: Glycosmis parviflora, Essential oil, Meloidogyne incognita, Sitophilus zeamais, Tribolium castaneum, Contact toxicity

Tropical Journal of Pharmaceutical Research is indexed by Science Citation Index (SciSearch), Scopus, International Pharmaceutical Abstract, Chemical Abstracts, Embase, Index Copernicus, EBSCO, African Index Medicus, JournalSeek, Journal Citation Reports/Science Edition, Directory of Open Access Journals (DOAJ), African Journal Online, Bioline International, Open-J-Gate and Pharmacy Abstracts

\section{INTRODUCTION}

Glycosmis represents a rather clear-cut genus within the tribe Clauseneae of the Aurantioideae subfamily of the Rutaceae comprising about 40 species and about 12 species was found in China [1]. Its range of distribution is centered in south and southeastern Asia and extends to south China and Taiwan as well as to New Guinea and north Australia. Glycosmis parviflora (Sims) Little (syn.: G. citrifolia (Willd.) Lindley) is a shrub or tree, mainly distributed in Southeastern China: Fujian, Guangdong, Guangxi, Guizhou, Hainan, Taiwan, and Yunnan Province and Japan, Myanmar, and Vietnam [1]. Its roots and stem bark have been used as a folk medicine in the treatment of skin itch, scabies, boils and skin ulcers [2]. Phytochemical analyses of $G$. parviflora led to the isolation of a number of different carbazole, acridone, and quinoline alkaloids, quinazolines and sulfur-containing amides as well as coumarins, flavonoids [2-7]. 
During the screening program for new agrochemicals from Chinese medicinal herbs and wild plants, the essential oil of $G$. parviflora aerial parts was found to possess insecticidal and nematicidal toxicities against root-knot nematode, Meloidogyne incognita (Kofoid and White) Chitwood and two grain storage insects (maize weevils, Sitophilus zeamais Motsch and red flour beetles, Tribolium castaneum Herbst). However, literature survey indicated no report on the volatile constituents and nematicidal/insecticidal activity of $G$. parviflora; thus, we decided to investigate the chemical constituents and nematicidal/ insecticidal activities of the essential oil of $G$. parviflora against .

\section{EXPERIMENTAL}

\section{Plant collection and identification}

Fresh aerial parts (10 kg) of G. parviflora were harvested from the suburb of Nanning City $\left(22.8^{\circ} \mathrm{N}, 108.3^{\circ} \mathrm{E}\right.$, Guangxi Zhuang Autonomous Region, China) in August 2010. The plant sample was identified by Dr. Liu, (College of Life Sciences, Beijing Normal University, Beijing 100875, China) and a voucher specimen (no. $\mathrm{CMH}-X i a o h u a s h a n x i a o j u-G u a n g x i-2010-08)$ was deposited in the Department of Entomology, China Agricultural University (Beijing 100193, China).

Extraction and purification of essential oil

To obtain the volatile oil, the air-dried sample was first ground to a powder using a grinding mill (Retsch Mühle, Germany), then soaked in water at a ratio of $1: 4(w / v)$ for $1 \mathrm{~h}$, prior to hydrodistillation using a round bottom flask over a period of $6 \mathrm{~h}$. Separation of the essential oil from the aqueous layer was done in a separatory funnel, using the non-polar solvent, $n$-hexane. The hexane layer was evaporated using a vacuum rotary evaporator (BUCHI Rotavapor R124, Switzerland). The residual oil was dried over anhydrous $\mathrm{Na}_{2} \mathrm{SO}_{4}$ and kept in a refrigerator (4 $\left.{ }^{\circ} \mathrm{C}\right)$ for subsequent experiments.

\section{Analysis of the essential oil}

Capillary gas chromatography was performed using Hewlett-Packard 5890 gas chromatograph equipped with a flame ionization detector and fused silica capillary column HP-5 (5\% diphenyl and $95 \%$ dimethylpolysyloxane, $30 \mathrm{~m} \times 0.25$ $\mathrm{mm}, \quad 0.25 \mu \mathrm{m}$ film thickness); injector and detector temperatures were $270{ }^{\circ} \mathrm{C}$ and $300{ }^{\circ} \mathrm{C}$, respectively. The components of the essential oil were separated by the GC and identified by mass spectrometry (GC-MS) using Agilent
$6890 \mathrm{~N}$ gas chromatography coupled to Agilent 5973N mass selective detector. GC settings were as follows: the initial oven temperature was held at $60{ }^{\circ} \mathrm{C}$ for $1 \mathrm{~min}$ and ramped at $10{ }^{\circ} \mathrm{C}$ $\mathrm{min}^{-1}$ to $180{ }^{\circ} \mathrm{C}$ where it was held for $1 \mathrm{~min}$, and then ramped at $20{ }^{\circ} \mathrm{C} \min ^{-1}$ to $280{ }^{\circ} \mathrm{C}$ and held there for $15 \mathrm{~min}$. The sample $(1 \mu \mathrm{L}$, diluted $1: 100$ in acetone) was injected, with a split ratio of 1:10. The carrier gas was helium at a flow rate of 1.0 $\mathrm{ml} \min ^{-1}$. Spectra were obtained over the scan range 20 to $550 \mathrm{~m} / \mathrm{z}$ at 2 scans $\mathrm{s}^{-1}$. Most constituents were identified by gas chromatography by comparison of their retention indices with those published in the literature or with those of authentic compounds available in our laboratories. The retention indices were determined in relation to a homologous series of $n$-alkanes $\left(\mathrm{C}_{8}-\mathrm{C}_{24}\right)$ under the same operating conditions. Further identification was made by comparison of their mass spectra with those stored in NIST 05 and Wiley 275 libraries or with mass spectra from literature [8]. Relative percentages of the oil components were calculated based on GC peak areas without using correction factors.

\section{Rearing of nematode and insects}

Maize weevils, S. zeamais and red flour beetles, $T$. castaneum were obtained from our laboratory cultures maintained in the dark in incubators at $29-30^{\circ} \mathrm{C}$ and $70-80 \%$ R.H. T. castaneum was reared on wheat flour mixed with yeast $(10: 1$, $\mathrm{w} / \mathrm{w})$ while $S$. zeamais were reared on whole wheat at 12 - $13 \%$ moisture content [using Kett's grain moisture tester (Model PB-1D2, Kett Electric Laboratory, Japan)] in glass jars (diameter $85 \mathrm{~mm}$, height $130 \mathrm{~mm}$ ). Unsexed adult weevils/beetles used in all the experiments were one week old. All containers housing insects and the petri dishes used in experiments were made insect-escape proof with a coating of polytetrafluoroethylene (Fluon, Blades Biological, UK).

Second stage juveniles of the root-knot nematode, $M$. incognita were obtained from a pure culture that was previously initiated by egg masses and propagated on tomatoes (Solanum lycopersicum) in the glasshouse [9]. Egg masses were manually picked using sterilized forceps from heavily infected roots (40 days after incubation). These egg masses were washed in distilled water, placed in a $750 \mu \mathrm{m}$ (15- mesh) sieves $(8 \mathrm{~cm}$ in diameter) containing crossed layers of tissue paper in Petri-dishes with water just deep enough to contact the egg masses and the dishes were incubated at $25-26{ }^{\circ} \mathrm{C}$ to obtain freshly hatched second stage juveniles [9]. Only the second stage juveniles collected within $48 \mathrm{~h}$ were used. 


\section{Contact toxicity test}

The contact toxicity of the essential oil against $S$. zeamais and $T$. castaneum was measured as described by Liu and Ho [10]. Range-finding studies were run to determine the appropriate testing concentrations of the oil of G. parviflora aerial parts. A serial dilution of the oil (15.0, 12.0, $9.0,6.5$, and $5.0 \%$.) was prepared in $n$-hexane. Aliquots of $0.5 \mu \mathrm{L}$ per insect were topically applied dorsally to the thorax of the weevils/beetles, using a Burkard Arnold microapplicator (Burkard Scientific Supply, Rickmansworth, England). Controls were determined using $0.5 \mu \mathrm{L} n$-hexane per insect. Ten insects were used for each concentration and control, and the experiment was replicated six times. Both the treated and control weevils/beetles were then transferred to glass vials (10 insects/vial) with culture media [wheat flour mixed with yeast $(10: 1, w / w)]$ and kept in incubators at $29-30^{\circ} \mathrm{C}$ and $70-80 \%$ relative humidity. Mortality was observed after $24 \mathrm{~h}$. The insects were considered dead if appendages did not move when probed with a camel brush. The observed mortality data were corrected for control mortality using Abbott's formula.

\section{Nematicidal toxicity bioassay}

The nematicidal activity of the essential oil against the root-knot nematodes was measured as described by $\mathrm{Li}$ et al. [9]. Range-finding studies were run to determine the appropriate testing concentrations. A serial dilution of the essential oil (five concentrations, dissolved first in $10 \mu \mathrm{L}$ ethanol) was prepared in $\mathrm{H}_{2} \mathrm{O}$ solution with $2 \%$ DMSO. Aliquots of $\mathrm{H}_{2} \mathrm{O}(20 \mu \mathrm{L})$ containing ca. 100 juveniles were transferred to vials to which $980 \mu \mathrm{L}$ of the solution containing ethanol extract was added. The vials were kept on a hood at $25{ }^{\circ} \mathrm{C}$. The inactive juveniles were counted every $24 \mathrm{~h}$ for $72 \mathrm{~h}$. After the last count, the inactive juveniles were maintained in distilled $\mathrm{H}_{2} \mathrm{O}$ for $24 \mathrm{~h}$ to observe their revival. Six repetitions for each treatment were performed using $\mathrm{H}_{2} \mathrm{O}$ and a $2 \%$ DMSO in $\mathrm{H}_{2} \mathrm{O}$ solution as well as a $2 \%$ DMSO in $\mathrm{H}_{2} \mathrm{O}$ solution containing $10 \mu \mathrm{L}$ ethanol as negative controls. The experiments were repeated three times. Carbofuran (commerical nematicide) was purchased from National Center of Pesticide Standards (8 Shenliao West Road, Tiexi District, Shenyang 110021 , China) and used as a positive control.

\section{Statistical analysis}

The results from all replicates in contact toxicity and nematicidal activity were subjected to Probit analysis using PriProbit Program V1.6.3 to determine $\mathrm{LD}_{50}$ and $\mathrm{LC}_{50}$ values, respectively [11]. Samples for which the $95 \%$ fiducial limits did not overlap were considered no significantly different.

\section{RESULTS}

The essential oil yield of $G$. parviflora aerial parts was $0.64 \%$ ( $\mathrm{v} / \mathrm{w}$ based on dry weight) and the density of the concentrated oil was $0.77 \mathrm{~g} / \mathrm{ml}$. A total of 37 components were identified in the essential oil, accounting for $97.3 \%$ of the total oil (Table 1). The main components of the essential oil were (Z)-caryophyllene (20.6\%), methyl isoeugenol (11.1\%), (Z)- $\beta$-ocimene (8.9\%), $\alpha$ cubebene $(6.4 \%)$ and nerolidol $(5.4 \%)$ followed by aromandendrene (4.9\%) and y-pyronene (4.7 $\%$ ) (Table 1). Monoterpenoids represented 10 of the 37 compounds, corresponding to $26.5 \%$ of the whole oil while 20 of the 37 constituents were sesquiterpenoids $(53.0 \%$ of the crude essential oil).

The essential oil possessed strong contact toxicity against $S$. zeamais and $T$. castaneum adults with $\mathrm{LD}_{50}$ values of $41.7 \mu \mathrm{g} /$ adult and 22.6 $\mu \mathrm{g} /$ adult, respectively (Table 2 ). Moreover, the oil also exhibited strong nematicidal activity against $M$. incognita with an $\mathrm{LC}_{50}$ value of $92.84 \mu \mathrm{g} / \mathrm{ml}$ (Table 3).

\section{DISCUSSION}

The main components of the essential oil of $G$. parviflora aerial parts were (Z)-caryophyllene (20.6\%), methyl isoeugenol (11.1\%), (Z)- $\beta$ ocimene $(8.9 \%)$, a-cubebene $(6.4 \%)$ and nerolidol (5.4\%). Genus Glycosmis comprises about 40 species in the world and about 12 species was found in China [1]. However, Chemical composition of only one species [ $G$. pentaphylla (Cor.)] essential oil has been measured so far. The essential oil of $G$. pentaphylla barks collected from India mainly contained 2-undecanone (58.1\%) and 2tridecanone (23.4\%) [12]. However, the major components of essential oil of $G$. pentaphylla collected from $\mathrm{Ha}$ Tinh, Vietnam were $\beta$-pinene $(27.4 \%)$, limonene $(42.4 \%)$, and $\beta$ caryophyllene $(3.5 \%)$ while that harvested from Nghe An, Vietnam contained $\beta$-pinene $(24.4 \%)$, limonene $(31.7 \%)$, and $\beta$-caryophyllene $(11.1 \%)$ [13].

The essential oil of $G$. parviflora exhibited nematicidal activity against the root-knot nematode. Compared with a synthetic insecticide, carbofuran $\left(\mathrm{LC}_{50}=72.29 \mu \mathrm{g} / \mathrm{ml}\right)$, the essential oil of $G$. parviflora exhibited the same 
Table 1: Chemical constituents of essential oil of Glycosmis parviflora

\begin{tabular}{|c|c|c|c|}
\hline $\begin{array}{l}\text { Peak } \\
\text { no. }\end{array}$ & Compound & $\boldsymbol{R}^{*}$ & $\begin{array}{l}\text { Peak } \\
\text { area }(\%)\end{array}$ \\
\hline 1 & a-Pinene & 939 & 2.2 \\
\hline 2 & $\beta$-Pinene & 974 & 0.1 \\
\hline 3 & $\beta$-Myrcene & 991 & 0.9 \\
\hline 4 & $\delta$-3-Carene & 1016 & 3.5 \\
\hline 5 & Limonene & 1029 & 1.6 \\
\hline 6 & (Z)- $\beta$-Ocimene & 1035 & 8.9 \\
\hline 7 & Linalool & 1094 & 3.5 \\
\hline 8 & Allo-ocimene & 1139 & 0.7 \\
\hline 9 & Camphor & 1143 & 0.4 \\
\hline 10 & Dihydroedulan I & 1293 & 0.4 \\
\hline 11 & 4-Vinylguaiacol & 1318 & 0.5 \\
\hline 12 & Y-Pyronene & 1338 & 4.7 \\
\hline 13 & a-Cubebene & 1345 & 6.4 \\
\hline 14 & Dehydro-ar-ionene & 1355 & 0.7 \\
\hline 15 & $\beta$-Elemene & 1389 & 0.7 \\
\hline 16 & Methyl Eugenol & 1403 & 1.7 \\
\hline 17 & (Z)-Caryophyllene & 1409 & 20.6 \\
\hline 18 & $\beta$-Caryophyllene & 1420 & 0.5 \\
\hline 19 & Aromandendrene & 1436 & 4.9 \\
\hline 20 & a-Caryophyllene & 1454 & 0.6 \\
\hline 21 & Elixene & 1456 & 0.1 \\
\hline 22 & Y-Muurolene & 1473 & 2.6 \\
\hline 23 & $\beta$-Neoclovene & 1475 & 0.9 \\
\hline 24 & Germacrene D & 1485 & 0.5 \\
\hline 25 & $\beta$-Selinene & 1490 & 1.1 \\
\hline 26 & $\begin{array}{l}\text { Methyl } \\
\text { isoeugenol }\end{array}$ & 1500 & 11.1 \\
\hline 27 & Bicyclogermacrene & 1513 & 0.9 \\
\hline 28 & $\delta$-Cadinene & 1523 & 0.5 \\
\hline 29 & Nerolidol & 1563 & 5.4 \\
\hline 30 & Spathulenol & 1572 & 3.7 \\
\hline 31 & $\begin{array}{l}\text { Caryophyllene } \\
\text { oxide }\end{array}$ & 1583 & 0.5 \\
\hline 32 & Viridiflorol & 1588 & 0.7 \\
\hline 33 & $\begin{array}{l}\text { Isoaromadendrene } \\
\text { epoxide }\end{array}$ & 1594 & 0.6 \\
\hline 34 & Isoelemicin & 1596 & 2.5 \\
\hline 35 & a-Cadinol & 1654 & 0.8 \\
\hline 36 & $\begin{array}{l}\text { Eudesma-4,11- } \\
\text { dien-2-ol }\end{array}$ & 1691 & 1.0 \\
\hline \multirow[t]{5}{*}{37} & Phytol & 2119 & 0.9 \\
\hline & Total identified & & 97.3 \\
\hline & Monoterpenoids & & 26.5 \\
\hline & Sesquiterpenoids & & 53.0 \\
\hline & Others & & 17.8 \\
\hline
\end{tabular}

${ }^{*} R I=$ retention index as determined on a HP-5MS column using the homologous series of n-hydrocarbons level of toxicity against $M$. incognita. Moreover, the essential oil of $G$. parviflora exhibited stronger nematicidal toxicity against the root-knot nematode, e.g. essential oil of Kadsura heteroclita [9] and Chenopodium ambrosioides [22]. The above findings indicated the essential oil of $G$. parviflora shows potential to be developed as a possible natural nematicide for control of the root-knot nematodes.

The essential oil of $G$. parviflora exhibited contact toxicity against $S$. zeamais and $T$. castaneum adults. When compared with the positive control (pyrethrum extract, $L_{50}=4.3 \mu \mathrm{g} /$ adult and 0.4 $\mu \mathrm{g}$ /adult, respectively)[14], the essential oil of $G$. parviflora demonstrated 10 and 63 times less acute toxicity against $S$. zeamais and $T$. castaneum adults. However, compared with the other essential oils in the literature, the essential oil of $G$. parviflora exhibited stronger or the same level of contact toxicity against $S$. zeamais and $T$. castaneum adults. Examples are essential oils of K. heteroclita [9], Illicium fragesii [15], I. simonsii [16], I. pachyphyllum [17], Caryopteris incana [18], Artemisia capillaries, A. mongolica [19], A. giraldii, A. subdigitata [20] and Murraya exotica [21].

Among the main constituents of the essential oil of G. parviflora, methyl isoeugenol, (Z)- $\beta$ ocimene and nerolidol have been demonstrated to exhibit insecticidal and acaricidal activities against several insect pests/mites, e.g. house fly Musca domestica [23], American house dust mite (Dermatophagoides farinae), European house dust mite (D. pteronyssinus) and adult mould mites (Tyrophagus putrescentiae) [24], twospotted spider mite (Tetranychus urticae) [25], and the yellow fever mosquito, Aedes aegypti larvae [26]. The isolation and identification of the bioactive compounds in the essential oil of $G$. parviflora are of utmost importance so that their potential application in controlling stored-product pests and nematodes can be fully exploited. The above findings suggest that the essential oil of $G$. parviflora can play an important role in stored

Table 3: Contact toxicity of essential oil of Glycosmis parviflora against Sitophilus zeamais (SZ) and Tribolium castaneum (TC) adults

\begin{tabular}{llllll}
\hline INSECT & Treatment & $\begin{array}{l}\mathbf{L D}_{50} \\
(\mu \mathrm{g} / \text { adult })\end{array}$ & $\begin{array}{l}\mathbf{9 5 \%} \text { fiducial } \\
\text { limits }\end{array}$ & Slope \pm SE & Chi square $\left(\mathbf{x}^{2}\right)$ \\
\hline SZ & Essential oil & 41.7 & $37.03-48.5$ & $4.2 \pm 0.5$ & 33.6 \\
& Pyrethrum & 4.3 & $3.9-4.7$ & - & - \\
TC & extract & & & \\
& Essential oil & 22.6 & $20.1-25.1$ & $4.1 \pm 0.6$ & 11.2 \\
& $\begin{array}{l}\text { Pyrethrum } \\
\text { extract }\end{array}$ & 0.4 & $0.3-0.4$ & - & - \\
\hline
\end{tabular}

* Liu et al [19] 
Table 2: Nematicidal activity of essential oil of Glycosmis parviflora against Meloidogyne incognita juvenile

\begin{tabular}{|c|c|c|c|c|}
\hline Treatment & $\begin{array}{c}\mathrm{LD}_{50} \\
(\mu \mathrm{g} / \mathrm{mL})\end{array}$ & 95\% fiducial limits & Slope \pm SE & Chi square $\left(\mathrm{x}^{2}\right)$ \\
\hline Essential oil & 92.84 & $83.73-101.59$ & $4.56 \pm 0.42$ & 11.69 \\
\hline Carbofuran & 72.29 & $37.86-117.97$ & $6.23 \pm 0.51$ & 13.57 \\
\hline
\end{tabular}

grain protection and nematode control and reduce the need for the same, and also the risks associated with of synthetic insecticides/ nematicides. However, for the practical application of the essential oil as a novel insecticide/nematicide, further studies on the safety of the essential oil to humans and on development of formulations are necessary to improve the efficacy and stability and to reduce cost.

\section{CONCLUSION}

The essential oil of $G$. parviflora aerial parts demonstrated some activity against maize weevils and red flour beetles as well as root-knot nematodes but needs to be further evaluated for safety in humans and to enhance its activity.

\section{ACKNOWLEDGEMENT}

This work was funded by the Hi-Tech Research and Development of China 2011AA10A202 and National New-Drug Innovation Project 2009ZX09501-014. The authors thank Dr. QR Liu of the College of Life Sciences, Beijing Normal University, Beijing 100875, for the identification of the plant.

\section{REFERENCES}

1. Huang CC. Flora Reipublicae Popularis Sinicae. Science Press, Beijing, China, 1997, Vol 43(2), pp 124-126. http://www.efloras.org/florataxon.aspx?flora_id=2 \&taxon id=200012451

2. Leu YL, Chan YY, Wu TS, Teng CM, Chen KT. Antiplatelet aggregation principles from Glycosmis citrifolia. Phytotherapy Res 1998; 12: S77-S79.

3. Ono T, Ito C, Furukawa H, Wu TS, Kuoh CS, Hsu KS. Two new acridone alkaloids from Glycosmis species. $J$ Nat Prod 1995; 58: 1629-1631.

4. Wu TS, Chang FC,Wu PL. Flavonoids, amidosulfoxides and an alkaloid from the leaves of Glycosmis citrifolia. Phytochemistry 1995; 39: 1453-1457.

5. Ito $\mathrm{C}$, Kondo $\mathrm{Y}, \mathrm{Wu}$ TS, Furukawa $H$. Chemical constituents of Glycosmis citrifolia (Willd.) Lindl. Structures of four new acridones and three new quinolone alkaloids. Chem Pharm Bull 2000; 48 . 65-70.

6. Negi N, Yu J, Ushijima K, Ikeda S, Takemura Y, Ju-ichi M, Wu TS, Ito C, Furukawa $H$. Two new dimeric acridone alkaloids from Glycosmis citrifolia. Chem Pharm Bull 2004: 52: 362-364.

7. Rahmani M, Serang M, Hashim NM, Sukari MA, Ee GCL, Ali AM, Ismail. Alkaloids and sulphur-containing amides from Glycosmis citrifolia and Glycosmis elongate. Sains Malaysiana 2010; 39: 445-451.
8. Adams RP. Identification of Essential Oil Components by Gas Chromatograph /Mass Spectrometry. $4^{\text {th }}$ ed. Allured Publishing Corpoartion, Carol Stream, USA, 2007.

9. Li HQ, Bai CQ, Chu SS, Zhou L, Du SS, Liu ZL, Liu QZ. Chemical composition and toxicities of the essential oil derived from Kadsura heteroclita stems against Sitophilus zeamais and Meloidogyne incognita. J Med Plants Res 2011; 5: 4943-4948.

10. Liu ZL, Ho SH. Bioactivity of the essential oil extracted from Evodia rutaecarpa Hook $f$. et Thomas against the grain storage insects, Sitophilus zeamais Motsch. and Tribolium castaneum (Herbst). J Stored Prod Res 1999; 35: 317-328.

11. Sakuma M. Probit analysis of preference data. Appl Entomol Zool 1998; 33: 339-347.

12. Ahmed $R$, Choudhury $S$, Vajczikova I, Leclercq PA. Essential oils of Glycosmis pentaphylla (Cor.). A new report from Assam, India. J Essent Oil Res 2000; 12: 471-474.

13. Le VH, Nguyen TMH. Chemical composition of the essential oils of Glycosmis pentaphylla Corr. growing in Ha Tinh and Nghe An. Tap Chi Duoc Hoc 2007; 47: $34-35$ (in Vietnamese with English abstract).

14. Liu ZL, Liu QR, Chu SS, Jiang GH. Insecticidal activity and chemical composition of the essential oils of Artemisia lavandulaefolia and Artemisia sieversiana from China. Chem Biodiv 2010; 7: 2040-2045.

15. Wang CF, Liu P, Yang K, Zeng Y, Liu ZL, Du SS, Deng ZW. Chemical composition and toxicities of essential oil of Illicium fragesii fruits against Sitophilus zeamais. Afr J Biotechnol 2011; 10: 18179-18184.

16. Chu SS, Liu SL, Jiang GH, Liu ZL. Composition and toxicity of essential oil of Illicium simonsii Maxim (Illiciaceae) fruit against the maize weevils. Rec Nat Prod 2010; 4: 205-210.

17. Liu P, Liu XC, Dong HW, Liu ZL, Du SS, Deng ZW. Chemical composition and insecticidal activity of the essential oil of Illicium pachyphyllum fruits against two grain storage insects. Molecules 2012; 17: 14870-14881.

18. Chu SS, Liu QZ, Zhou LG, Du SS, Liu ZL. Chemical composition and toxic activity of essential oil of Caryopteris incana against Sitophilus zeamais. Afr J Biotechnol 2011; 10: 8476-8480.

19. Liu ZL, Chu SS, Liu QR. Chemical composition and insecticidal activity against Sitophilus zeamais of the essential oils of Artemisia capillaris and Artemisia mongolica. Molecules 2010; 15: 26002608.

20. Chu SS, Liu ZL, Du SS, Deng ZW. Chemical composition and insecticidal activity against Sitophilus zeamais of the essential oils derived from Artemisia giraldii and Artemisia subdigitata. Molecules 2012; 17: 7255-7265.

21 Li WQ, Jiang CH, Chu SS, Zuo MX, Liu ZL. Chemical composition and toxicity against Sitophilus zeamais and Tribolium castaneum of the essential oil of Murraya exotica aerial parts. Molecules 2010; 15: 5831-5839.

22. Bai CQ, Liu ZL, Liu QZ. Nematicidal constituents from the essential oil of Chenopodium ambrosioides aerial parts. E-J Chem 2011; 8(S1): 143-148. 
23. Samarasekera $R$, Kalhari KS, Weerasinghe IS Insecticidal activity of essential oils of Ceylon Cinnamomum and Cymbopogon species against Musca domestica. J Essent Oil Res 2006; 18: 352354.

24. Sung BK, Lee HS. Chemical composition and acaricidal activities of constituents derived from Eugenia caryophyllata leaf oils. Food Sci Biotechnol 2005; 14: 73-76.
25. Cavalcanti SCH, Niculau ES, Blank AF, Camara CAG, Araujo IN, Alves PB. Composition and acaricidal activity of Lippia sidoides essential oil against twospotted spider mite (Tetranychus urticae Koch). Bioresource Technol 2009; 101: 829-832.

26. Chantraine JM, Laurent D, Ballivian C, Saavedra G, Ibanez $R$, Vilaseca $L A$. Insecticidal activity of essential oils on Aedes aegypti larvae. Phytotherapy Res 1998; 12: 350-354. 